\title{
Livro Didático e Gêneros Textuais: Tessituras entre a Presenca e a Diversidade na Proposta de Manuais de Ensino
}

\author{
Débora Amorim Gomes da COSTA-MACIEL* \\ Jonathas de Paula CHAGURI**
}

\footnotetext{
* Doutora em Educação pela Universidade Federal de Pernambuco (UFPE). Professora Adjunta da Universidade de Pernambuco (UPE), Campus Mata Norte. E-mail: debora.amorim@upe.br

** Doutor em Educação pela Universidade Estadual de Maringá (UEM). Professor Adjunto da Universidade de Pernambuco (UPE), Campus Mata Norte. E-mail: jonathas.chaguri@upe.br
}

\begin{abstract}
Resumo:
Este artigo analisa a presença e a diversidade de gêneros de texto apresentados pela coleção de livros didáticos EJA Moderna (2013) destinada à Educação de Pessoas Jovens, Adultas e Idosas. Para a sua realização, tomamos como análise três volumes da referida obra e a investigamos a partir da análise documental, à luz da abordagem qualitativa. Os resultados sinalizam para um conjunto de possibilidades e limites diante dos gêneros propostos. Há de se destacar o lugar secundário com que se trata os gêneros da ordem do argumentar e a pouca atenção para a progressão textual que poderia garantir um trabalho com o mesmo gênero/ ordem no escopo dessa modalidade. Este cenário realça a necessidade de o(a) professor(a) intervir nas propostas didáticas da coleção, com vistas a garantir o direito dos(as) aluno(as) ampliar a capacidade linguístico-discursiva. Portanto, essa análise permitiu-nos afirmar que essa passividade na proposta de progressão textual orienta-se por uma concepção de educação dominante porque exclui a ordem do argumentar, ligado ao desenvolvimento da capacidade crítica do(a) aluno(a). Desse modo, a diversidade textual direciona-se sem uma proposta de progressão textual adequada.
\end{abstract}

Palavras-chave:

Livro Didático; Gêneros Textuais; EJAI.

Signum: Estudos da Linguagem, Londrina, v.24, n.2, p. 43-58, ago. 2021

Recebido em: 04/03/2021

Aceito em: 16/06/2021

${ }^{1}$ Dados coletados com apoio da Fundação de Amparo à Ciência e Tecnologia do Estado de Pernambuco (FACEPE). 


\section{Livro Didático e Gêneros Textuais: Tessituras entre a Presença e a Diversidade na Proposta de Manuais de Ensino}

Débora Amorim Gomes da Costa-Maciel; Jonathas de Paula Chaguri

\section{INTRODUÇÃo}

Como os livros didáticos organizam os gêneros textuais no âmbito de sua proposta de ensino? Esta pergunta fomentou o objetivo desde artigo, que se compromete em analisar a presença e a diversidade de gêneros textuais apresentados no âmbito de uma coleção de livros didáticos destinados aos anos iniciais da Educação de Pessoas Jovens, Adultas e Idosas (EJAI).

Trazemos o livro didático (LD) para à baila da discussão, considerando-o como suporte, pois no contexto educacional brasileiro, ele se constitui como um dos principais apoio textual disponibilizado para as escolas públicas. Por vezes, ele se representa como o "instrumento principal que guia a ação docente" (ALBUQUERQUE; FERREIRA, 2019, p. 250). O livro pode ser observado como "instrumentos de poder" (CASSIANO, 2007), uma vez que se configura como um portador de ideologias sistêmicas, devendo, portanto, ser alvo de estudos e de reflexões constantes.

Nos livros didáticos são apresentados diferentes gêneros textuais. Eles adentram a escola, mediados pelo suporte livro, estrategicamente pensados para cumprir variados objetivos. O acesso e o trabalho com gêneros "permite que os alunos tenham contato com os diversos textos que circulam na sociedade e, dessa forma, dar-lhes a oportunidade de utilizar e vivenciar o conhecimento da escrita e, de fato, se apropriar da linguagem" (NEVES, 2011, p. 01). Olhar o ensino a partir dos gêneros textuais é uma busca pela a valorização das atividades de linguagem em contextos de usos reais (MARCUSCHI, 2001).

No âmbito da EJAI, entendemos que o acesso ao LD e a diversidade de gêneros textuais podem ser defendidos como a garantia de um direito. Este direito se inicia com o acesso à escola. Ele está assegurado pela LDB no 9.394 de 20 de dezembro de 1996 (BRASIL, 1996). Além disso, os(as) alunos(as) que não tiveram acesso ou oportunidade de continuar os estudos na idade adequada, há o documental nacional do Plano Nacional de Educação (BRASIL, 2014). Tanto este documento (BRASIL, 2014) como a Lei de Diretrizes e Bases (BRASIL, 1996) reforçam a importância do acesso e ao trato com a pluralidade de gêneros textuais que favorecem a vivência de uso da linguagem em diferentes contextos sociais.

Apesar de o Plano Nacional de Educação (BRASIL, 2014, online) explicitar a necessidade de implementar ações de alfabetização de jovens e adultos com garantia de continuidade da escolarização básica, observamos que no contexto atual houve a descontinuação de políticas relevantes para a EJAI, como por exemplo, o Programa Nacional do Livro Didático da EJA (PNLD/EJA), que realizava a avaliação e entrega gratuita de livros didáticos próprios para o trabalho com a referida modalidade.

A útima entrega de livros didáticos destinados a EJAI às escolas públicas, nos municipios da Zona da Mata Norte no estado de Pernambuco, por exemplo, ocorreu no ano de 2014 e, desde então, não houve atualizações. A coleção EJA Moderna é uma dessas obras que chegaram às escolas no referido ano. Contudo, por não haver uma coleção substituta e/ou atualização, a coleção EJA permanece sendo utilizada pela comunidade escolar. 
Diante da escassez de trabalhos que tratem dessa temática, este texto realça a sua pertinência, pois amplia a discussão sobre as temáticas "gêneros textuais", "EJA" e "livro didático", possibilitando pensar sobre o tema no âmbito dos estudos acadêmicos e contribuir com o trabalho de docentes, gestores, coordenadores e formadores que atuam cotidianamente com modalidade, bem como com os sujeitos que a compõem, a partir do compartilhamento das informações nas diferentes esferas educacionais.

Em face ao exposto, este texto está organizado da seguinte forma: primeiro apresentaremos os aspectos metodológicos desenhados para o alcance dos objetivos propostos. Por conseguinte, trazemos as bases teóricas que estruturaram a reflexão do objeto discutido neste espaço enunciativo. E, como não poderia deixar de ser, apresentaremos as discussões e os resultados observados a partir da imersão dos dados.

\section{Presença e Diversidade de Gêneros Textuais: Percurso Metodológico}

Este trabalho pode ser caracterizado como sendo de caráter documental e com uma abordagem qualitativa. Para a sua realização, tomamos como corpos de análise 3 (três) volumes de livros didáticos da coleção EJA Moderna (2013a, 2013b, 2013c) destinadas aos anos iniciais do ensino fundamental $\left(1^{\circ}\right.$ e $2^{\circ}$ segmentos) da Educação de Jovens e Adultos(as). Segundo a coleção (EJA MODERNA, 2013a, 2013b, 2013c), o objetivo é de dar suporte para o trabalho docente dos primeiros segmentos da modalidade EJAI.

Utilizamos como critério de escolha dessas obras, a sua adoção por municípios que compõem a Zona da Mata Norte no estado de Pernambuco. No processo seletivo, foram coletados os exemplares junto a 6 (seis) Secretarias de Educação dos municípios de Carpina, Lagoa do Carro, Tracunhaém, Paudalho, Nazaré da Mata e Vicência. Estes municípios que compõem a Zona da Mata Norte adotaram a coleção supracitada como suporte para as práticas educativas na modalidade da EJAI.

Uma vez que buscamos analisar a presença e a diversidade de gêneros textuais apresentados no âmbito da coleção EJA Moderna (2013a, 2013b, 2013c), a obra encontra-se organizada de forma mista, isto é, de forma interdisciplinar para o primeiro volume (EJA MODERNA, 2013a) e disciplinar para o segundo e terceiro volume (EJA MODERNA, 2013b, 2013c). A partir desta configuração, então, mapeamos os gêneros textuais e conceituamos no quadro abaixo. A saber:

\begin{tabular}{|c|c|c|c|}
\hline \multirow[t]{2}{*}{ LIVROS } & $1^{\circ}$ VOLUME & \multirow[b]{2}{*}{$\square$ Interdisciplinar } & $2^{\circ}$ E $3^{\circ}$ VOLUMES \\
\hline & $\begin{array}{l}\text { Todos os gêneros textuais foram } \\
\text { identificados sem diferenciação de } \\
\text { componente curricular. }\end{array}$ & & $\begin{array}{l}\text { Localizamos os protótipos } \\
\text { apresentados em quadros } \\
\text { organizativos que descriminam os } \\
\text { componentes curriculares, tais como: } \\
\text { língua portuguesa; matemática; } \\
\text { história; geografia; ciências e artes. }\end{array}$ \\
\hline
\end{tabular}

Fonte: Os autores (2021)

Esse movimento, agrupado no quadro acima, posiciona-nos à compreensão de que os gêneros textuais perpassam as práticas sociais nos diferentes campos de saberes e que o seu uso não é exclusividade do ensino de língua portuguesa (GUEDES; SOUZA, 2007). Na análise dos dados, caminhamos conforme os pressupostos da utilização de elementos da análise de conteúdo categorial proposto por Bardin (1977).

Estes pressupostos preveem elementos de localização, identificação, organização e avaliação das informações contidas no referido documento, a partir de uma reflexão da fonte original, apresentando os fatos contextualizados, conforme preconizam Ludke e André (2008). Por conseguinte, ancorados 
na proposta de Bardin (1977), cuja perspectiva analítica aponta as etapas da pré-análise, exploração do material, tratamento dos resultados de inferências e interpretação, seguimos com o propósito de identificar os gêneros textuais tratados na coleção.

Após a identificação dos protótipos ensinados nos livros da coleção, iniciamos a análise, considerando os aspectos tipológicos e as capacidades de linguagem. Nessa mesma etapa, vale destacar que analisamos a existência de progressão textual e as estratégias de ensino promovidas nesse contexto. $\mathrm{Na}$ fase do tratamento dos resultados de inferências e interpretação, analisamos a partir das discussões à luz de uma literatura no âmbito dos estudos da linguagem. Isto posto, passamos a configurar os pressupostos teóricos que possibilitam os encaminhamentos para a discussão dos dados.

\section{Gêneros Textuais e Livro Didático: Bases Teóricas em Discussão}

Na medida em que avançam o tempo e a sociedade, o conhecimento acerca dos gêneros textuais torna-se cada vez mais indispensável, visto que a comunicação ocorre mediada por eles. Na ausência dos gêneros, "a comunicação verbal seria quase impossível” (BAKHTIN 1953; 1979 p. 302 apud DOLZ; SCHNEUWLY 2004, p. 24).

No contexto dos gêneros textuais, consideramos necessário definir a compreensão sobre eles. Os gêneros são artefatos culturais e históricos constituídos sob o intuito de atender as demandas sociais de comunicação, segundo esclarecem Dolz e Schneuwly (2004). Os gêneros, portanto, contribuem para ordenar atividades comunicativas nos quais estão presentes nas esferas sociais e, por conseguinte, ganham sentidos quando são projetados para o outro. Em outras palavras, quando falamos ou escrevemos, realizamos essas ações em função do(a) interlocutor(a). É o outro que nos faz ter uma atitude responsiva diante das situações de enunciação, sejam elas orais ou escritas.

Os gêneros textuais podem ser observados em agrupamentos, que se organizam definidos por Dolz e Schneuwly (2004, p. 43) a partir dos aspectos tipológicos, podendo apresentar-se nas "ordens do narrar, argumentar, descrever, relatar ou expor". Os agrupamentos propostos pelos pesquisadores de Genebra consideram as capacidades de linguagem globais. Por sua vez, elas, então, são definidas por causa dos domínios sociais de comunicação e das capacidade de linguagens dominante.

A compreensão das capacidades de linguagem ocorre porque para produção de um gênero, elas são acionadas mesmo que de forma inconsciente e, assim, acabam por compor os enunciados (orais ou escritos) diante da esfera de circulação social ao qual o gênero textual ganha sentido, considerando seus interlocutores, com propósitos reais diante do ato responsivo que exercem em seu discurso enquanto prática social.

Em síntese, os grupamentos seguem três critérios para a construção da progressão: (1) domínios sociais de comunicação: "correspondem às grandes finalidades sociais legadas ao ensino, respondendo as necessidades de linguagem em expressão escrita e oral, em domínios essenciais de comunicação em nossa sociedade (inclusive a escola)" (DOLZ; SCHNEUWLY, 2004, p. 58-59); (2) aspectos tipológicos: "retomam, de maneira flexível, certas distinções tipológicas, que já figuram em manuais e guias curriculares" (DOLZ; SCHNEUWLY, 2004, p. 58-59) e (3) capacidades de linguagem dominantes: "sejam relativamente homogêneos quanto às capacidades de linguagem implicadas no domínio dos gêneros agrupados" (DOLZ; SCHNEUWLY, 2004, p. 58-59).

Estes agrupamentos estão organizados tipologicamente a partir de suas capacidades de linguagem, tais como: narrar (mimeses da ação por meio da criação da intriga no domínio do verossímil); relatar (representação pelo discurso de experiências vividas, situadas no tempo); argumentar (sustentação, refutação e negociação de tomadas de posição); do expor (apresentação textual de diferentes formas de saberes); descrever (regulação mútua de comportamentos). "Este arranjo observa as regularidades 
linguísticas, para definir capacidades globais a serem ampliadas no processo de escolarização" (DOLZ; SCHNEUWLY, 2004, p. 60).

Resgatamos, neste artigo, o modelo teórico-metodológico do Interacionismo Sociodiscursivo (ISD) por entendermos que tal proposta pode nos ajudar a discutir, a partir do cenário apresentado pela coleção analisada, como os gêneros textuais propostos pela obra, ao serem observados, sob a ótica do agrupamento, podem contribuir com a ampliação da formação do educando da EJAI.

Um aspecto importante a mencionar é a compreensão da dialética dos postulados teóricos de Paulo Freire e do quadro teórico-metodológico do ISD. Devido ao fato de estarmos tratando de um trabalho que apresenta uma ação, uma síntese e uma nova ação e, assim, sucessivamente (sem esgotar a possibilidade de fim, mas de um contínuo exercício da práxis), entendemos o seu caráter histórico e dialético materializado nos gêneros textuais.

Neste caso, o professor e educador Paulo Freire, bem como o quadro teórico-metodológico do ISD podem e devem ser considerados como uma dimensão dialética por se constituírem por um contexto social que é determinado por um cenário econômico que se relaciona com o trabalho do homem na sociedade. Logo, um gênero textual como receita culinária, bilhete, carta pessoal, poesia, podcasts, e-mail, debates e dentre outros, são produtos discursivos porque materializam a necessidade de uma interação verbal entre seus interlocutores (o "eu” e o "outro") que se constituem historicamente. E, por assim ser, é dialético porque assume uma atitude responsiva entre seus interlocutores, ou seja, mantém uma relação dialógica, evocando as contradições a partir do trabalho dos sujeitos na sociedade, mas que é mediada pelos sentidos históricos que determinam a identidade dos enunciados (orais ou escritos) elaborados por seus interlocutores. Por isso, Freire (2001) e demais pesquisadores (CRISTOVÃO, 2009; COSTAHÜBES, 2009; CHAGURI, 2019) que dialogam com o quadro teórico-metodológico do ISD fazem-nos compreender que os gêneros textuais nos dão acesso ao direito dos bens culturais criado pela humanidade.

Entendemos, portanto, que além de os gêneros textuais serem bens culturais (FERREIRA, 1986), os livros didáticos também o são. Eles se configuram como um dos principais documentos que dão suporte a uma diversidade de gêneros textuais. Sabemos que é por meio do trabalho com os gêneros que os(as) alunos(as) fortalecem as práticas discursivas, entendidas por este texto como a oralidade, leitura e escrita. Por essa razão, o trabalho com a análise linguística não deve ser trabalhado de forma isolada, mas, sobretudo, deve estar sempre alinhada pelas práticas discursivas nas aulas de língua portuguesa.

Dessa forma, faz-se relevante observar quais são os gêneros indicados nos LD. O conhecimento da diversidade textual presente nesses materiais pode contribuir para o fortalecimento das práticas discursivas (oralidade, leitura e escrita) de modo que favoreça a participação com fins reais e significativos dos(as) alunos(as) da EJAI nos diferentes contextos de uso da língua.

É mais prazeroso não só para o professor ensinar, mas para o(a) aluno(a) da EJAI aprender a função social de um texto do que somente os aspectos gramaticais. Por exemplo, os(as) alunos(as) da EJAI, ao aprenderem sobre o recurso linguístico "voz passiva", a partir do estudo de um texto, neste caso, a carta de reclamação, compreenderão que este tipo de gênero textual evoca a voz de alguém que está reclamando de um produto com defeito ou serviço não realizado de forma satisfatória e, assim, o(a) aluno(a) da EJAI entende o porquê, quando e como usar o recurso linguístico "voz passiva" na elaboração de uma carta de reclamação.

Práticas como estas, que consideram o texto como produto discursivo, onde alguém diz algo para o outro alguém (GERALDI, 1997), distancia-se de práticas meramente reprodutivistas que consideram o texto como pretexto para fins de estudos puramente gramaticais sem reais propósitos e significados na prática social dos(as) alunos(as) da EJAI. 
Tal conhecimento sobre os textos que utilizamos em sala de aula é fundamental, especialmente na EJAI, uma vez que é necessário considerar os sujeitos e seus contextos. E, como apontam Dolz e Schneuwly (2004, p.72-73), as interpretações das práticas de linguagem "dependem da identidade social dos atores e das representações que eles têm dos usos possíveis da linguagem e das funções que eles privilegiam de acordo com sua trajetória". Mediante ao que até aqui expomos neste texto, passamos, então, agora, para os resultados e discussão dos dados coletados.

\section{Livro Didático e Gêneros Textuais: À Guisa da Discussão}

O LD é uma ferramenta que faz parte do trabalho de qualquer professor(a) em sala de aula. Não só nas aulas de língua portuguesa e de língua estrangeira moderna que são os componentes curriculares na educação básica que se ocupam por estudar a língua como objeto de estudo da linguística aplicada, mas também, o LD é amplamente usado nos demais componentes curriculares, tais como: matemática; física; química; história; geografia; filosofia; sociologia; biologia; ciências e artes. Ele serve para levar o(a) aluno(a) para a apropriação do conhecimento e ao(a) professor(a) desenvolver seu trabalho em sala de aula.

Segundo Gimenez (2009, p. 8 - grifo da autora), os livros didáticos "se tomados como veículos de teorias mais adequadas e, portanto, superiores ao conhecimento construído na prática pelo próprio professor, podem subjugá-lo, tornando-o seu "fiel seguidor"”. Contudo, se os(as) professores(as) considerarem a realidade local de sua comunidade escolar no qual exercem a sua docência, considerando, então, a realidade de seus(as) alunos(as), o LD pode ser um instrumento que está à disposição de contextos específicos a fim de alcançar a função social da escola pública que, atualmente, é garantir o aprendizado a todo(a) cidadão(a) de forma democrática.

Desse modo, propor uma discussão em torno do agrupamento dos gêneros textuais nos materiais didáticos, é uma forma de dar oportunidade para a ciência resolver criticamente os problemas historicamente construídos e, por conseguinte, compreendermos quando um material didático está aliado a uma prática meramente reprodutivista e de artificialidade do trabalho com o texto ou quando ele está ligado a uma prática social que considera o agrupamento dos textos como forma de interação social entre seus interlocutores, traçando, assim, resultados esperados com propósitos reais e significativos para além do muro da escola.

Por essa razão, engajamo-nos, então, a discutir o repertório de gêneros presente no primeiro volume da coleção EJA Moderna (2013a). Para isso, observamos a seguir os agrupamentos e gêneros textuais encontrados, bem como a ocorrência de protótipos disponíveis.

Quadro 2 - Coleção EJA Moderna do Primeiro Volume de Caráter Multidisciplinar

\begin{tabular}{|c|l|}
\hline Agrupamentos & \multicolumn{1}{|c|}{ Gêneros Textuais/Ocorrência } \\
\hline Narrar & $\begin{array}{l}\text { Advinha (01), Canção (05), Cantiga (01), Cordel (01), Lenda (01), Música (04) } \\
\text { Parlenda (01), Poema }{ }^{2} \text { (08), Quadrinha (04), Tira (04), Trava-língua (01), Diálogo (01), Rap } \\
(01)\end{array}$ \\
\hline $\begin{array}{c}\text { Argumentar } \\
\text { Descrever }\end{array}$ & Embalagem (01), Receita (02) \\
\hline
\end{tabular}

\footnotetext{
${ }^{2}$ Não podemos esquecer que os gêneros podem se manifestar em tipologias distintas. Nesse recorte, tivemos a intenção de alocar o poema na ordem do narrar, uma vez que o conteúdo temático da proposta nos deu o suporte para tal classificação.
} 


\begin{tabular}{|l|l|}
\hline \multirow{3}{*}{ Expor } & Anúncio (01), Anúncio de Classificado (01), Campanha (01), Cartaz (01), Carteira de \\
& Trabalho (01), Cheque (02), Conta de Água (01), Cadastro de Pessoas Físicas/ CPF (01), \\
& $\begin{array}{l}\text { Diagrama (05), Glossário (16), Gráfico (04), Lista (03), Logotipo (01), Mapa (02), Placa } \\
\text { (01), Placa de Trânsito (02), Planta (02), Registro Geral de Nascimento (01), Tabela (07), } \\
\\
\text { Título de Eleitor (01), Verbete de Dicionário (01) }\end{array}$ \\
\hline Relatar & Bilhete (01), Biografia (02), Certidão de Nascimento (01) \\
\hline
\end{tabular}

Fonte: Coleção EJA Moderna (2013a)

O quadro acima evidencia 41 (quarenta e um) gêneros no primeiro volume da coleção (EJA MODERNA, 2013a). Nesta análise, observamos que a coleção com os agrupamentos do narrar, do expor, do descrever e do relatar, preocupa-se em possibilitar ao professor um encaminhamento didáticopedagógico cuja as práticas discursivas (oralidade, leitura e escrita) sejam aprendidas pelos(as) aluno(as) da EJA como uma prática social, ou seja, o discurso como prática social é constituído como conteúdo estruturante que se materializa nas práticas discursivas, viabilizando, portanto, ao(a) professor(a) os momentos adequados de se propor atividades linguísticas em função da mediação do estudo da língua enquanto produto discursivo.

Contudo, no que diz respeito à ordem do argumentar, observamos a ausência de protótipos de gêneros. Acreditamos que essa ausência pode representar, a priori, uma despreocupação em tratar, de modo focal, da referida ordem nesse contexto de alfabetização. Costa-Maciel, Barbosa e Bilro (2019) sinalizaram a despreocupação por editoras e/ou autores de livros didáticos por trabalhar com questões relacionadas à sustentação, refutação e negociação de tomadas de posição nos anos iniciais. Por essa razão, constatamos que o cenário se repete na proposta da obra que tomamos para análise nesta pesquisa.

É importante destacar que os gêneros textuais não compreendem modelos estanques. Portanto, os agrupamentos herdam essa característica. Isso significa que ao considerarmos um gênero textual como pertencente a um agrupamento, não estamos impondo que eles não possam pertencer ou transitar em outro agrupamento, pois, como sabemos, os textos podem apresentar características de mais de uma tipologia. É por isso que eles observam as capacidades de linguagens prevalentes dos gêneros.

No tocante aos gêneros, agora, observamos os modais dispostos no segundo volume da coleção (EJA MODERNA, 2013b), especificamente, na área de língua portuguesa.

Quadro 3 - Coleção EJA Moderna do Segundo Volume do Componente Curricular de Língua Portuguesa

\begin{tabular}{|c|c|}
\hline Agrupamentos & Gêneros Textuais \\
\hline Narrar & $\begin{array}{l}\text { Apólogo (01), Canção (02), Conto (01), Crônica (01), Fábula (03), Poema (05), } \\
\text { Quadrinho (06), Tira (07) }\end{array}$ \\
\hline Argumentar & Charge (01) \\
\hline Descrever & Envelope (03) \\
\hline Expor & $\begin{array}{l}\text { Anúncio de Classificado (06), Capa de Livro (04), Cartão-Postal (01), Cartaz (01), } \\
\text { Classificado de serviço (02), Glossário (19), Página de dicionário (04), Quadro (17), } \\
\text { Verbete de Dicionário (06) }\end{array}$ \\
\hline Relatar & $\begin{array}{l}\text { Autobiografia (02), Bilhete (05), Biografia (26), Carta Pessoal (02), Depoimento (04), } \\
\text { Diário pessoal (03), Recado (01), Reportagem (01) }\end{array}$ \\
\hline
\end{tabular}

Fonte: Coleção EJA Moderna (2013b)

No primeiro momento, observamos um quantitativo de 27 (vinte e sete) gêneros no componente curricular de língua portuguesa. Foram 8 (oito) gêneros narrativos, a saber: apólogo; canção; conto; 
crônica; fábula; poema; quadrinho e tira. Nesse volume (EJA MODERNA, 2013b), o único gênero argumentativo foi a charge, no entanto, não como objeto de ensino e estudo, mas como um pretexto para realização de outra atividade. No descritivo, temos apenas o envelope de carta. Já os que puderam ser categorizados como expositivos são 9 (nove) gêneros: anúncio classificado; capa de livro; cartãopostal; cartaz; classificado de serviço; glossário; página de dicionário; quadro e verbete de dicionário. Por conseguinte, para a ordem do relatar, foram evidenciados 8 (oito) gêneros: autobiografia; bilhete; biografia; carta pessoal; depoimento; diário pessoal; recado e reportagem.

Entre os gêneros dispostos no quadro anterior, os que são considerados como objeto de estudo pela obra são: bilhete; recado; carta pessoal; cartão-postal; diário pessoal; verbete de dicionário; anúncio de classificado; depoimento; tira; fábula; apólogo; biografia e autobiografia.

Os demais gêneros são usados como suporte e/ou complemento para o ensino dos gêneros que estão sendo explorados e/ou atividades. Como, por exemplo, um poema para iniciar o ensino do gênero biografia ou uma canção numa atividade. Contudo, vale destacar que este segundo volume da coleção (EJA MODERNA, 2013b) apresenta uma variedade de gêneros textuais que fazem parte da esfera do cotidiano não só do(a) aluno(a) da EJAI, mas de qualquer pessoa. São eles: envelope; cartaz; bilhete e recado. Nossa análise, portanto, nos autoriza afirmar que o agrupamento destes gêneros textuais que fazem parte do cotidiano possibilita aos(as) professores(as) de língua portuguesa condições de garantir aos(as) alunos(as) da EJAI, o aperfeiçoamento da leitura enquanto prática discursiva, construindo, assim, a competência leitora. Segundo Dell'Isola (1996), a leitura é lugar de produção de sentido, lugar de constituição de significado, a partir da relação leitor-texto. Portanto, a leitura realizada a partir desses gêneros é considerada um produto pessoal. Em outras palavras, a leitura passa assumir um caráter individual, sendo determinado pelas condições sociais, culturais, históricas e afetivas e ideológicas do leitor.

Logo, o(a) aluno(a) da EJAI ao ser exposto ao estudo da língua portuguesa por meio desses gêneros, mesmo que inconscientemente, produzirá diversas leituras do mesmo texto, dependendo do momento e das relações com o produto discursivo. Por exemplo, um dos autores deste artigo, trabalhou por 4 (quatro) anos com a Educação de Jovens e Adultos (EJA), ensinado língua portuguesa. Ao longo desse período, observou-se que, por questões de fóruns íntimos e pessoais que não convém explicitar na argumentação do texto, os(as) alunos(as) da EJAI perdiam suas oportunidades de trabalho. Nestas ocasiões, conforme o exemplo que será explicado a seguir, coincidiu-se de o(a) professor(a) estar trabalhando o gênero bilhete aliado variação linguística, comum e presente neste tipo de gênero textual.

Para a ocasião, um aluno, do gênero masculino, com faixa etária entre 30 (trinta) a 35 (trinta e cinco) anos de idade, residente na zona urbana em um município do noroeste do estado do Paraná, chamou a atenção da turma e do professor em uma atividade realizada em grupo. $O$ fato foi que este aluno havia participado na semana em que ocorreu a aula de língua portuguesa de uma entrevista de emprego em uma fábrica de torneiras da região. $\mathrm{Na}$ entrevista, foi solicitado a ele pelo recrutador dos recursos humanos que deixasse um bilhete para quem seria o encarregado por sua produção no setor da fábrica. Para tanto, ao escrever o bilhete, ele direcionou um breve recado a quem de direito devia pertencer. Após a leitura do bilhete, tanto o recrutador como o encarregado do setor da fábrica sentiramse lisonjeados porque o candidato (no caso o aluno da EJA) despediu-se usando a saudação "Abçs". Os demais candidatos à vaga, segundo relato do aluno, não usaram nenhuma saudação para despedir-se ou quando usaram foi de forma não adequada, segundo o relato dado por ele na aula.

O que queremos enunciar neste artigo com essa argumentação é que o "outro", neste caso, configurado pelo recrutador dos recursos humanos e pelo encarregado de um dos setores da fábrica, atribuíram sentido ao que foi produzido de forma social pelo aluno da EJA, isto é, seu bilhete tinha propósitos reais e interlocutores reais. Por essa razão, concordamos com Dell’'Isola (1996) que a leitura, 
neste exemplo, ocorrido no cotidiano de um aluno da EJAI, produziu sentido diante do contexto histórico que se circunscrevia os atores sociais naquela ocasião.

Assim, continuamos a apresentação dos dados coletados para este trabalho. Então, imersos na obra, observamos a presença de gêneros distribuídos nos demais componentes curriculares.

\begin{tabular}{|c|c|}
\hline Componente Curricular & Gêneros Textuais \\
\hline Matemática & $\begin{array}{l}\text { Anúncio (04), Glossário (02), Gráfico (07), Logomarca (01), Mapa (02), } \\
\text { Notícia (01), Placa (08), Planta (09), Quadro (10), Tabela (09), Tira (01) }\end{array}$ \\
\hline História e Geografia & $\begin{array}{l}\text { Artigo de opinião (01), Calendário (01), Glossário (05), Gráfico (01), Linha do } \\
\text { tempo (01), Logotipo (01), Mapa (13), Placa (01), Planta (03) } \\
\text { Quadro (01), Relato (01) }\end{array}$ \\
\hline Ciências & $\begin{array}{l}\text { Artigo científico (01), Glossário (01), Gráfico (02), Mapa (01), Primeira Página de } \\
\text { Jornal (01), Texto Instrucional (01). }\end{array}$ \\
\hline Artes & $\begin{array}{l}\text { Artigo (01), Biografia (01), Canção (01), Convite (01), Glossário (10), Texto } \\
\text { Instrucional (03) }\end{array}$ \\
\hline
\end{tabular}

Fonte: Coleção EJA Moderna (2013b)

Evidenciamos 34 (trinta e quadro) gêneros expostos nas outras disciplinas, sendo 11(onze) em matemática, 11(onze) em história e geografia, 6 (seis) em ciências e 7(sete) em artes. Faz-se necessário destacar que os gêneros evidenciados nas demais disciplinas não são ensinados, estão apenas expostos para subsidiar as atividades de conteúdos ligados aos referidos componentes curriculares.

O terceiro volume da coleção (EJA MODERNA, 2013b) corresponde a um exemplar de 400 (quatrocentas) páginas, dividido por disciplina em 3 (três) unidades, sob as respectivas temáticas: Direitos e Deveres do Cidadão; Participação e Sociedade e Patrimônio Nacional.

Um aspecto importante a mencionar nesta análise é a presença do gênero glossário que aparece em todas os volumes dos demais componentes curriculares. Como dito anteriormente, esse gênero não está proposto neste terceiro volume para fins de estudo, mas, ele aparece 2 (duas) vezes em matemática, 5 (cinco) vezes em história e geografia, 1 (uma) vez em ciências e 10 (dez) vezes em artes. Cumpre-nos, portanto, retratar uma observação que na qualidade de pesquisadores julgamos ser pertinentes para o propósito da análise.

Partindo de uma concepção sociointeracionista da linguagem, afirmamos que o texto nunca está acabado, ou seja, não é um produto pronto, mas, sobretudo, um dispositivo de produção de sentidos. Neste contexto, o(a) professor(a) atento ao aparecimento do mesmo gênero textual em diversos momentos da obra, pode explorar junto aos(as) seus(as) alunos(as) a função social que o glossário busca apresentar em cada componente curricular.

Em uma pesquisa realizada por Silva (2015), houve a aplicação de uma intervenção didáticopedagógica para alunos(as) do nono ano do ensino fundamental em uma escola pública a fim de elaborarem glossários de termos de diferentes disciplinas. E, após essa tarefa, a intervenção propôs a soletração dos itens lexicais trabalhados. A proposta elaborada por Silva (2015) evidencia que o gênero glossário assume uma perspectiva interdisciplinar, pois sua pesquisa trabalhou com "palavras e termos das disciplinas de português, ciências e matemática” (SILVA, 2015, p. 31).

Para este fim, o trabalho com o glossário pode instaurar-se por duas práticas: a metalinguística ou epilinguística. No caso de um ensino voltado para a metalinguística, a sistematização e a descrição da língua é o foco dado para atividades que busca priorizar um conjunto de elementos linguísticos próprios para falar sobre a língua. Neste caso, atividades como classifique o termo da oração abaixo e defina os substantivos ou adjetivos são típicos dessa prática de ensino. 
Por outro lado, a epilinguística busca provocar no(a) aluno(a) e no(a) professor(a) um posicionamento crítico sobre o funcionamento da língua pautado nos modos de construção da língua. Nesta prática de ensino, as atividades sobre a língua "devem ser desenvolvidos articulados às práticas de leitura e produção textual” (SILVA, 2011, p. 72). Em outras palavras, a ênfase nos usos como objeto de ensino das práticas discursivas (oralidade, leitura e escrita) direcionam-se para "vários outros objetos de ensino (estruturais, textuais, discursivos, normativos), apresentados e retomados sempre que necessário" (MENDONÇA, 2006, p. 207).

É, então, por isso, que diante dos dados coletados, esta análise permite-nos afirmar que a proposta elaborada por Silva (2015) para trabalhar com o glossário de forma interdisciplinar pode ser usado adequadamente em uma prática de epilinguística. Isso ocorre porque a prática-com o glossário nas aulas de língua portuguesa ou em outros componentes curriculares "é efetivada pelo levantamento, por parte dos professores, de dúvidas coletivas e individuais dos alunos, seguido de consultas aos dicionários impressos ou online, como também de outras atividades práticas, com o objetivo de que [...] favoreça a análise dos textos especializados" (SILVA, 2015, p. 26).

Contudo, caso a proposta de Silva (2015) estivesse ancorada por uma prática que abordasse o uso do glossário de forma isolada com ênfase nos conteúdos gramaticais como objeto de ensino, então, a metalinguística seria a prática de ensino adota para essa ocasião. O que queremos enunciar nesta análise é que, conforme propõe Bagno (2009), não existe forma certa ou errada de ensinar e aprender uma língua, mas sim, formas adequadas. Vejamos, agora, quais gêneros estão disponíveis no exemplar do terceiro volume (EJA MODERNA, 2013c) e como eles se agrupam para o estudo da língua portuguesa.

Quadro 5 - Coleção EJA Moderna do Terceiro Volume de Língua Portuguesa

\begin{tabular}{|c|l|}
\hline Agrupamentos & \multicolumn{1}{|c|}{ Gêneros Textuais } \\
\hline Narrar & $\begin{array}{l}\text { Canção (02), Conto (01), Conto Popular/Tradicional (02), Cordel (04) } \\
\text { Crônica (05), Poema (04), Rap (01), Texto Teatral (02), Tira (08) }\end{array}$ \\
\hline $\begin{array}{c}\text { Argumentar } \\
\text { Descrever }\end{array}$ & Carta de Leitor (02), Carta de Reclamação (02) \\
\hline Expor & Lei (02), Manual de Instrução (05) \\
\hline Relossário (19), Gráfico (01), Quadro (16) & $\begin{array}{l}\text { Biografia (20), Manchete de jorna l (02), Notícia (08), Reportagem (01) } \\
\text { Texto Jornalístico (03) }\end{array}$ \\
\hline
\end{tabular}

Fonte: Coleção EJA Moderna (2013c)

No terceiro volume da coleção (EJA MODERNA, 2013c), há 21 (vinte e um) gêneros textuais presentes no livro de língua portuguesa. Sendo 9 (nove) narrativos. São eles: canção; conto; conto popular/ tradicional; cordel; crônica; poema; rap; texto teatral e tira. Com relação aos gêneros argumentativos, são explorados 2 (dois) deles: a carta de leitor e a carta de reclamação.

Quanto aos gêneros descritivos, temos a lei e o manual de instrução. Na ordem do expor aparecem 3 (três) gêneros: glossário; gráfico e quadro. Apesar da pouca diversidade, eles são encontrados diversas vezes no decorrer do livro. Por conseguinte, evidenciamos 5 (cinco) gêneros que podem ser considerados da ordem do relatar: biografia; manchete de jornal; notícia; reportagem e texto jornalístico.

Observamos que os gêneros efetivamente ensinados neste exemplar de língua portuguesa (EJA MODERNA, 2013c) correspondem a 9 (nove) gêneros: lei; manual de instrução; carta de leitor; carta de reclamação; notícia; crônica; cordel; conto e texto teatral. Em um total de 21 (vinte e um) gêneros mapeados neste volume da coleção (EJA MODERNA, 2013c), apenas 9 (nove) estão organizados para fins de estudo pelos(as) alunos(as) da EJAI, ou seja, didatizados para o ensino. 
Esse posicionamento de agrupar os gêneros e, depois, escolher quais deles serão organizados para fins de ensino pelo(a) professor(a) e de estudo pelo(a) aluno(a), não é uma tarefa desproposital e, nem mesmo, realizada sem cautela. Pelo contrário, os autores da obra, possuem uma enorme responsabilidade quando se trata de didatizar os textos que, na maioria das vezes, foram acionados para cumprirem um papel de pretexto para fins de estudos gramaticais. Nessa direção, Lemes (2013, p. 125) corrobora que "compreender os caminhos teóricos e transpô-lo para um material didático exige deles uma alteração em suas concepções de língua(gem) como também encontrar caminhos para uma didatização satisfatória". Esse movimento é condicionado pela compreensão de que "a prática de análise linguística, está articulada com outros módulos de ensino, leitura e produção de texto".

A escolha deste ou aquele gênero textual como objeto de ensino em uma coleção de livros didáticos merece, sem dúvida, um estudo mais aprofundado a fim de engajarmo-nos criticamente por um processo de ensino e aprendizagem que favoreça uma postura cidadã e autônoma a todos(as) que realizam o árduo, mas, prazeroso exercício da pesquisa científica. Por isso, propomo-nos a provocar outros pesquisadores a dedicaram-se a estudos posteriores a este texto sobre a escolha de didatização de gêneros textuais em materiais didáticos. Na próxima análise, então, passamos a discutir os gêneros expostos nos demais componentes curriculares.

Quadro 6 - Coleção EJA Moderna do Terceiro Volume dos Demais Componentes Curriculares

\begin{tabular}{|c|c|}
\hline Componente Curricular & Gêneros Textuais \\
\hline Matemática & $\begin{array}{l}\text { Anúncio (08), Cardápio (01), Conta de água (01), Gráfico (20), Lista (01), Logomarca } \\
\text { (01), Mapa (04), Notícia [Manchete] (03), Placa (02), Planta (06), Propaganda (02), } \\
\text { Quadro (02), Tabela (31). }\end{array}$ \\
\hline História e Geografia & $\begin{array}{l}\text { Biografia (01), Canção (01), Capa de livro (01), Cartaz (01), Cartaz de Campanha (02) } \\
\text { Carteira de Trabalho (01), Carteira Nacional de Habilitação (01), Certidão de Nascimento } \\
\text { (01), Certificado de Reservista (01), Charge (01), CPF (01), Glossário (02) } \\
\text { Lei (01), Mapa (02), Organograma (01), Passaporte (01), Quadro (03), RG (01), Título de } \\
\text { Eleitor (01). }\end{array}$ \\
\hline Ciências & $\begin{array}{l}\text { Cartaz (02), Glossário (04), Gráfico (03), Lista (01), Mapa (04), Quadro (04), Relato (01) } \\
\text { Roteiro cultural (02) }\end{array}$ \\
\hline Artes & $\begin{array}{l}\text { Artigo de opinião (01), Charge (01), Entrevista (01), Glossário (06), Lista (01), Painel } \\
\text { (01), Tabela (01) }\end{array}$ \\
\hline
\end{tabular}

Fonte: Coleção EJA Moderna (2013a; 2013b; 2013c)

Observamos dentro de outros componentes curriculares a presença de 48 (quarenta e oito) gêneros textuais. 13 (treze) estão disponíveis em matemática; 19 (dezenove) estão alocados em geografia e história; 8 (oito) agrupados em ciências e 7 (sete) em artes. Assim como no volume do $2^{\circ}$ ano, o presente tomo não apresenta o repertório de texto supracitado acima como objeto de ensino.

Considerando os 3 (três) volumes, observamos uma diversidade textual significativa que é expressa no total de 86 (oitenta e seis) gêneros das diversas ordens. No entanto, apenas alguns desses gêneros são tomados como objeto de ensino pela coleção. São 38 (trinta e oito) didatizados nos três volumes analisados (EJA MODERNA, 2013a, 2013b, 2013c) sendo 9 (nove) deles voltados para o ensino da prática discursiva oral (adivinha, cordel, conto, depoimento, lenda parlenda, quadrinha, recado, travalíngua) e 29 (vinte e nove) para a prática discursiva de produção textual escrita (anúncio classificado, apólogo, autobiografia, bilhete, biografia, carta do leitor, carta pessoal, carta de reclamação, classificado de emprego, classificado de serviço, certidão de nascimento, crônica, cartaz, diário pessoal, diálogo, embalagens/rótulos, fábula, leis, lenda, notícia, manchete de jornal, manual de instrução, texto teatral, tira, quadrinhos, RG, sinais de trânsito, título de eleitor, verbete de dicionário). 
Toda essa estimativa permite-nos compreender que os(as) autores(as) da coleção EJAI, optaram por priorizar a questão da produção textual escrita. Os(as) professores(as) de língua portuguesa e de literatura tem como principal objetivo promover o fortalecimento das práticas discursivas que, como já dito anteriormente neste texto, compreendemos por ser a oralidade, leitura e escrita. Isso deve ocorrer para que o(a) aluno(a) seja capaz de posicionar-se criticamente nas relações de poder a partir de sua própria visão de mundo. Desse modo, o seu referencial de signo e verdade caminha em direção para novos significados, proporcionando, assim, sua emancipação e autonomia no convívio social.

Isso significa que a fim de construirmos um ensino voltado para o trabalho com a oralidade, leitura e escrita, Antunes (2014) advoga que o ensino destas práticas discursivas não pode e nem deve sobrepor a importância de uma em detrimento de outra. Pelo contrário, o trabalho com as práticas discursivas deve ser realizado ativamente pelo(a) professor(a). Só assim, o(a) aluno(a) ampliará do domínio da oralidade, da leitura e da escrita de forma que ele(a) mesmo possa reelaborar seu ponto de vista (entendido como os enunciados orais e escritos) e, assim, "dominar aquilo que os dominantes dominam" (SAVIANI, 2007, p. 55), tendo em vista que o trabalho com o texto na sala de aula é histórico e dialético e, portanto, um bem cultural produzido pela humanidade.

Vejamos, agora, os gêneros textuais que são ensinados nos três volumes, considerando o agrupamento desses gêneros no quadro a seguir.

Quadro 7 - Ordem dos Gêneros Textuais Ensinados nos Volumes

\begin{tabular}{|c|c|c|c|}
\hline Ordem & $\begin{array}{c}\text { Gêneros Textuais } \\
\text { Volume } 1\end{array}$ & $\begin{array}{c}\text { Gêneros Textuais } \\
\text { Volume } 2\end{array}$ & $\begin{array}{c}\text { Gêneros Textuais } \\
\text { Volume } 3\end{array}$ \\
\hline Narrar & $\begin{array}{l}\text { Adivinha, Cordel } \\
\text { Lenda, Parlenda Quadrinha, } \\
\text { Trava-língua }\end{array}$ & $\begin{array}{l}\text { Apólogo, Fábula } \\
\text { Quadrinhos, Tira }\end{array}$ & $\begin{array}{l}\text { Conto tradicional, Cordel, } \\
\text { Crônica, Texto Teatral }\end{array}$ \\
\hline Relatar & Bilhete, Biografia & $\begin{array}{l}\text { Autobiografia, Bilhete, } \\
\text { Biografia, } \\
\text { Carta Pessoal, Depoimento, } \\
\text { Diário Pessoal, Recado }\end{array}$ & $\begin{array}{l}\text { Manchete de Jornal } \\
\text { Notícia }\end{array}$ \\
\hline Argumentar & ----- & ------ & $\begin{array}{l}\text { Carta do leitor } \\
\text { Carta de reclamação }\end{array}$ \\
\hline Expor & $\begin{array}{l}\text { Anúncio classificado, Cartaz, } \\
\text { Certidão de Nascimento, } \\
\text { Diálogo } \\
\text { Embalagens/Rótulo, RG, } \\
\text { Sinais de Trânsito, Título de } \\
\text { Eleitor }\end{array}$ & $\begin{array}{l}\text { Anúncio de Classificado } \\
\text { Classificado de Emprego } \\
\text { Classificado de Serviço } \\
\text { Verbete de Dicionário }\end{array}$ & ------ \\
\hline Descrever & ---- & ----- & $\begin{array}{l}\text { Leis } \\
\text { Manual de Instrução }\end{array}$ \\
\hline
\end{tabular}

Fonte: Coleção EJA Moderna (2013a; 2013b; 2013c)

Conforme o quadro acima, no primeiro volume da coleção são tratados os gêneros adivinha, anúncio, bilhete, biografia, cartaz, certidão de nascimento, cordel, diálogo embalagens/rótulos, lenda, parlenda, quadrinha, RG, sinais de trânsito, título de eleitor e trava-língua. Observamos a predominância de gêneros da ordem do narrar e do expor enquanto as ordens do argumentar e descrever não apresentam protótipos como objeto de ensino no volume.

Já no segundo volume, são trabalhados os gêneros, autobiografia, apólogo, anúncio, bilhete, biografia, classificado de emprego, classificado de serviço, fábula, carta pessoal, depoimento, diário pessoal, recado, tira, quadrinho e verbete de dicionário. Observamos que gêneros das ordens do argumentar e 
descrever não são tratados. No entanto, vemos que os gêneros didatizados no primeiro volume são explorados no segundo, dando-nos o sentido de progressão textual. Trata-se dos gêneros anúncio de classificado, bilhete e biografia.

No terceiro volume da coleção, são tomados como objetos de ensino os seguintes gêneros textuais: conto; cordel; crônica; carta de leitor; carta de reclamação; leis; manchete de jornal; notícia; manual de instrução e texto teatral. Observamos que apenas no terceiro volume há inserção de gêneros argumentativos e descritivos. Dos gêneros didatizados nos volumes anteriores, apenas o gênero cordel é tomado como objeto de ensino no volume em evidência que podemos relacionar a uma proposta de progressão. Portanto, vejamos, no quadro abaixo, os gêneros em progressão nos 3 (três) volumes da coleção.

Quadro 8 - Gêneros Textuais em Progressão nos Três Volumes da Coleção

\begin{tabular}{|l|l|l|}
\hline \multicolumn{1}{|c|}{ Volume 1 } & \multicolumn{1}{|c|}{ Volume 2 } & \multicolumn{1}{|c|}{ Volume 3 } \\
\hline $\begin{array}{l}\text { Anúncio de Classificado (p. 94), Bilhete } \\
\text { (p. 148), Biografia (p. 155), Cordel (p. 128) }\end{array}$ & $\begin{array}{l}\text { Anúncio de Classificado (p. 167), Bilhete (p. 11), } \\
\text { Biografia (p. 315). }\end{array}$ & Cordel (p. 262) \\
\hline
\end{tabular}

Fonte: Coleção EJA Moderna (2013a; 2013b; 2013c)

Os gêneros do quadro 8 (oito) são tratados considerando a ordem alfabética (anúncio de classificado, biografia e cordel) e a ordem dos volumes que são explorados (anúncio volume 1 e 2; biografia volume 1 e 2; cordel volume 1 e 3). Para Dolz e Schneuwly (2004), a progressão compreende a sistematização temporal do ensino, capaz de propiciar uma aprendizagem em espiral. Por isso, o sentido espiral a partir da premissa de que "um mesmo gênero poderia ser revisitado em diferentes momentos da escolarização" (SILVA; COSTA-MACIEL, 2017, p. 122) aumenta o grau de complexidade ao longo dos anos/momentos.

\section{Considerações Finais}

A análise apresentada nesse texto nos permite configurar dois cenários que são preocupantes. O primeiro trata-se do pouco quantitativo do agrupamento dos gêneros textuais no domínio da argumentação. Isso ocorre porque os gêneros textuais da ordem do argumentar são ferramentas para o desenvolvimento da capacidade crítica dos sujeitos. Eles estão ligados ao domínio social de comunicação de discussão de problemas sociais controversos e das capacidades de linguagem de sustentação, refutação e negociação de tomada de decisão (DOLZ; SCHNEUWLY, 2004). Logo, sua baixa ocorrência como objeto de estudo na coleção faz com que o(a) aluno(a) reproduza uma concepção de ensino a partir dos padrões determinados pela classe dominante, neste texto, entendido pelo LD que se materializa pelas ideologias marcadas de seus(as) autores(as).

O segundo cenário que se torna preocupante é a diversidade textual que ocupam um lugar passivo na coleção sem uma atenta proposta de progressão textual. Considerando os 3 (três) volumes e todos os volumes dos componentes curriculares analisados, verificamos um número expressivo que se traduz num total de 86 (oitenta e seis) gêneros das diversas ordens do narrar, do relatar, do argumentar, do expor e do descrever. Contudo, com uma proposta de progressão textual, identificamos na coleção, somente os gêneros anúncio de classificado, bilhete, biografia e cordel. Num total de 86 (oitenta e seis) gêneros, apenas 4 (quatro) estão elencados pelos autores para um ensino progressivo dentro da coleção.

Em termos de resultados finais, a concepção por uma educação que se orienta por padrões determinados por uma classe dominante que exclui a ordem do argumentar porque está ligado ao 
desenvolvimento da capacidade crítica do(a) aluno(a) e a diversidade textual sem uma proposta atenta progressão textual, obriga, sem sombras de dúvida, que o(a) professor(a) seja capaz de adaptar e/ ou complementar o livro adotado por sua escola e, em certos casos, lançar mão da produção de um novo material didático que atenda às necessidades linguístico-discursivo de seus alunos(as). Todo esse cenário remete-nos para precarização do trabalho docente, levando o(a) professor(a) a exaurir-se em sua prática didático-pedagógica.

\section{REFERÊNCIAS}

ALBUQUERQUE, Eliana Borges Correia de; FERREIRA, Andrea Tereza Brito. Programa nacional de livro didático (PNLD): mudanças nos livros de alfabetização e os usos que os professores fazem desse recurso em sala de aula. Ensaio: Avaliação e Políticas Públicas em Educação, v. 27, p. 250-270, 2019. Disponível em: https://www.researchgate.net/publication/330990076_Programa_nacional_de_livro_ didatico_PNLD_mudancas_nos_livros_de_alfabetizacao_e_os_usos_que_os_professores_fazem_ desse_recurso_em_sala_de_aula Acesso em 21 nov 2021

ANTUNES. I. O Professor de Língua: a urgência de programas de formação que lhe garantam uma nova identidade pedagógico-social. In: CHAGURI, J. P.; TONELLI, J. R. A. (Orgs.). Perspectivas Educacionais e Ensino de Linguas. Londrina: Eduel, p. 195-208, 2014.

BARDIN, Laurence. Análise de Conteúdos. Lisboa: Edições 70, 1977.

BAGNO, M. Preconceito Linguístico: o que é, como se faz. 51 ed. São Paulo: Edições Loyola, 2009.

BRASIL. Lei n. 9394 de 20 de dezembro de 1996. Diretrižes e Bases da Educação Nacional. Brasília: Senado Federal, Coordenação de Edições Técnicas, 2017.

BRASIL. Instituto Nacional de Estudos e Pesquisas Educacionais Anísio Teixeira. Plano Nacional de Educação (PNE 2014-2024). Brasília: Inep, 2015.

CASSIANO, C. C. F. O Mercado do Livro Didático no Brasil: da criação do Programa Nacional do Livro Didático (PNLD) à entrada do capital internacional espanhol (1885-2007). 234 f. 2007. Tese (Doutorado em Educação) - Pontifícia Universidade Católica de São Paulo. São Paulo, 2007.

CHAGURI, J. P. Uma Experiência Durante a Orientação da Produção Didático-Pedagógica no PDE no Ensino de Língua Portuguesa na Formação Continuada. Educere et Educare, Cascavel, v. 14, n. 33, p. 1-16, 2019.

COSTA-MACIEL, D. A. G.; BARBOSA, M. L. F. F.; BILRO, F. K. S. Gêneros textuais/discursivos e capacidades de linguagem dominante: análise dos livros didáticos de alfabetização destinados as escolas públicas brasileiras. In: ASSOCIAÇÃO NACIONAL DE PÓS-GRADUAÇÃO E PESQUISA EM EDUCAÇÃO. 39., 2019, Niterói. Anais... Niterói: UFF, 2019, p. 1-7.

COSTA-HÜBES, T. C. Reflexões Linguísticas sobre Metodologia e Prática de Ensino em Língua Portuguesa. Confluência, Rio de Janeiro, v. 1, n. 35, p. 129-146, 2009.

CRISTOVÃO, V. L. L. Desvendando Textos com o Interacionismo Socio Discursivo. In: ANTONIO, J. D.; NAVARRO, P. (Orgs.). O Texto como Objeto de Ensino, de Descrição Linguística e de Análise Textual e Discursiva. Maringá: Eduem, 2009. p. 49-57 
DOLZ, J.; SCHNEUWLY, B. Gêneros e progressão em expressão oral e escrita: elementos para reflexão sobre uma experiência Suíça (francófona). In: Dolz, Joaquim e Schneuwly, Bernard. Gêneros orais e escritos na escola. São Paulo: Mercado de Letras, 2004.

DELL'ISOLA, R. L. P. A Interação Sujeito-Linguagem em Leitura. In: MAGALHÃES, I. (Org.). As Múltiplas Faces da Linguagem. Brasília: UNB, 1996. p. 69-75.

ENCONTRO DE PESQUISAS E EXTENSÃO EM PROCESSOS EDUCACIONAIS, 2., 2018, Itumbiara. Anais [...]. Itumbiara: Instituto Federal de Goiás, Campus Itumbiara, 2018. 325 p. Tema: Alfabetização Científica: impactos no ensino, na pesquisa e na formação de professores.

GIMENEZ, T. Prefácio. In: DIAS, R.; CRISTOVÃO, V. L. L. (Org.). O Livro Didático de Lingua Estrangeira: múltiplas perspectivas. São Paulo: Mercado de Letras, 2009. p. 7-11.

EJA MODERNA. Educação de Jovens e Adultos: alfabetização. v. 1. São Paulo: Moderna, 2013a.

EJA MODERNA. Educação de Jovens e Adultos: anos iniciais do ensino fundamental. v. 2. São Paulo: Moderna, 2013b.

EJA MODERNA. Educaşão de Jovens e Adultos: anos iniciais do ensino fundamental. v. 3. São Paulo: Moderna, 2013c.

FERREIRA, A. B. H. Novo Dicionário Aurélio da Lingua Portuguesa. Rio de Janeiro: Editora Nova Fronteira, 1986.

FREIRE, P. A Importância do Ato de Ler: em três artigos que se completam. 42 ed. São Paulo: Cortez, 2001. (Questões da nossa época, v. 13)

GALVÃO, A. M. O.; SOARES, L. J. G. História da Alfabetização de Adultos no Brasil. In: ALBUQUERQUE, E. B. C.; LEAL, T. F. (Orgs.). A Alfabetização de Jovens e Adultos em uma Perspectiva do Letramento. Belo Horizonte: Autêntica, 2004. p. 27-58

GUEDES, P. C.; SOUZA, J. M. de. Leitura e Escrita são Tarefas da Escola e não só do Professor de Português. In: NEVES, I. C. B. (Org.) Ler e Escrever: compromisso de todas as áreas. 8 ed. Porto Alegre: UFRGS, 2007. p. 17 -22

GERALDI, J. W. Portos de Passagem. 4 ed. São Paulo: Martins Fontes, 1997.

IBGE. Pesquisa Nacional por Amostra de Domicílios Contínua. Instituto Brasileiro de Geografia Estatística. PNAD Contínua, 2018. Disponível online em: < https://biblioteca.ibge.gov.br/visualizacao/ livros/liv101657_informativo.pdf>. Acesso em 20 fev. 2021.

LUDKE, M.; ANDRÉ, M. E. D. A. Pesquisa em Educação: abordagens Qualitativas. Remp. ed. São Paulo: Ed. EPU, 2008.

MARCUSCHI, Luiz Antônio. Da fala para a escrita: atividades de retextualização. 2. ed. São Paulo: Cortez, 2001. 133 p.

MENDONÇA, M. Análise Linguística do Ensino Médio: um novo olhar, um novo objeto. In: BUNZEN, C.; MENDONÇA, M. (Orgs.). Português no Ensino Médio a Formação do Professor. 2 ed. São Paulo: Parábola, 2006. p.207-207 
NEVES, L. F. Tratamento dos gêneros textuais em um livro didático de alfabetização. 2011. Disponível em: $<$ http://jottaclub.com/wpcontent/uploads/2015/04/Tratamento-dos-g\%C3\%AAneros-textuais-emum-livro-did $\% \mathrm{C} 3 \% \mathrm{~A} 1$ tico-de-alfabetiza $\% \mathrm{C} 3 \% \mathrm{~A} 7 \% \mathrm{C} 3 \% \mathrm{~A} 3 \mathrm{ol}$.

pdf>. Acesso em 02 mar. 2021.

SILVA JÚNIOR. L. D. A Compreensão Docente a respeito das Dimensões Argumentativas no Contexto do Artigo de Opinião produrido por Alunos do Ensino Médio. 156 f. 2018. Dissertação (Mestrado Profissional em Educação) - Universidade de Pernambuco. Nazaré da Mata, 2018.

SAVIANI, D. Escola e Democracia: teorias da educação, curvatura da vara, onze teses sobre a educação política. 39 ed. Campinas: Autores Associados, 2007.

SILVA, A. et al. Desafios da Alfabetização de Jovens e Adultos: o programa Brasil Alfabetizado em foco. In: ALBUQUERQUE, E. B. C.; LEAL, T. F. (Orgs.). A Alfabetização de Jovens e Adultos em uma Perspectiva do Letramento. Belo Horizonte: Autêntica, 2004. p. 11-25

SILVA, H. I. Argumentar no Debate Regrado: reflexões sobre a prática docente no contexto da Educação de Jovens e Adultos. 153 f. 2019. Dissertação (Mestrado em Educação) - Universidade de Pernambuco, Campus Mata Norte. Nazaré da Mata, 2019.

SILVA, J. P., COSTA-MACIEL, D. A. G. Produção de Texto no Contexto da Progressão dos Gêneros Textuais: proposições do livro didático. Revista Educaşão em Questão, Natal, v. 55, n. 43, p. 115-138, 2017.

SILVA, W. R. Estudo da Gramática no Texto: demandas para o ensino e a formação do professor de língua materna. Maringá: Eduem, 2011.

SILVA, F. M. P. Glossário Escolar: uma construção do aluno. 117 f. 2015. Dissertação (Mestrado Profissional em Letras) - Universidade Federal de Uberlândia, Uberlândia. 2015.

SCHNEUWLY, B.; DOLZ, J. Gêneros Orais e Escritos na Escola. Trad. de Roxane Rojo; Glais Cordeiro. Campinas: Mercado de Letras, 2004. 